\title{
The Association between Ethnicity and Level of Education with Exclusive Breastfeeding Practice in the Context of the Place of Residence in Nigeria
}

Nkemdilim P Anazonwu ( $\sim$ nkemdilim.anazonwu@unn.edu.ng )

University of Nigeria

Chukwuedozie K Ajaero

University of Nigeria

Peter $\mathrm{O}$ Mbah

University of Nigeria

\section{Research}

Keywords: Ethnicity, Exclusive breast-feeding, Level of education, Nigeria, Place of residence

Posted Date: July 10th, 2020

DOI: https://doi.org/10.21203/rs.3.rs-40855/v1

License: (c) (i) This work is licensed under a Creative Commons Attribution 4.0 International License.

Read Full License 


\section{Abstract}

\section{Background}

While researches have been done separately on ethnicity and level of education as factors of exclusive breastfeeding (EBF) practice, there is dearth of studies on the peculiarities of EBF practice in the context place of residence as regards to the combined influence of ethnicity and level of education. To examine the association of ethnicity and level of education with exclusive breastfeeding (EBF) practice in urban and rural areas of Nigeria.

\section{Methods}

Data was from the Nigeria Demographic and Health Survey (NDHS) of 2018. The sample comprised of 16,982 urban and 24,834 rural women aged 15-49 years in all the 36 States and the Federal Capital Territory (FCT) of Nigeria. The outcome variable was exclusive breast-feeding (EBF) practice while the major predictor variables were ethnicity and level of education. Analyses of data were by descriptive statistics, Pearson Chi square and binary logistic regression at 0.05 level of significance.

\section{Results}

Higher education levels were significantly associated with decreased engagement in EBF practice in urban and rural areas while ethnic differences were significantly associated with EBF practice in the rural areas. Being aged 25-34 years $(O R=2.316 ; p=0.000)$ was significantly associated with increased odds of EBF practice in urban areas. Moreover, region of residence was significantly associated with EBF practice in the rural areas. Finally, in both rural and urban areas, households with more than two children were significantly associated with increased odds of EBF.

\section{Conclusions}

More sensitization campaigns on the need to incorporate EBF practice into formal employment work ethics where women with higher levels of education mostly work are needed in urban areas. In addition, ethnic practices, which promote EBF practices, should be encouraged in antenatal and postnatal clinics.

\section{Introduction}

Infants are at risk of negative health consequences associated with non-exclusive breastfeeding practice (EBF). Globally, $60 \%$ of the 10.9 million infant deaths annually occur due to inappropriate or suboptimal infant feeding practices and infectious disease and two-thirds of these deaths are attributable to suboptimal breastfeeding practices [1]. Suboptimal breastfeeding is responsible for 1.45 million deaths per year that is 4,000 deaths per day, 165 deaths per hour, or 3 deaths per minute [2]. This is because nearly $60 \%$ of the world's infants are missing out on the recommended six months of EBF [3], while about $40 \%$ of infants $0-6$ months old are exclusively breastfed [4]. The consequences of inappropriate infant feeding or non-EBF practice results to infection from gastro-intestinal diseases such as necrotizing 
enterocolitis (NEC), the occurrence of otitis media, and of several other bacterial infections such as meningitis, bacteremia, lower respiratory infections and botulism, infant mortality and morbidity [5-6]. On the other hand, exclusively breastfed children perform better on intelligence tests, will be less likely to be overweight or obese, will be less prone to diabetes later in life and have reduced risk of breast and ovarian cancers in women [7].

Nigeria lost 103,742 children to the deficit in breastfeeding in 2017 despite initiative programs to protect, promote and support EBF in the country and its benefits to infants, mothers, families and society [8]. Moreover, low breastfeeding rates continue to be evident in Nigeria despite widespread information regarding the benefits. According to a national survey, only $27 \%$ of children in the country were exclusively breastfed by their mothers, leaving a deficit of $73 \%$ that was denied the right [9]. This situation could be traceable to socio-cultural factors. Thus to ensure decline in infant's mortality and morbidity due to nonpractice of EBF, research on the combined influence of major socio-cultural factors such as education and ethnicity on EBF practice in Nigeria, especially in the rural-urban comparative context is important because the practice rate of EBF differed among ethnic groups and among urban and rural dwellers in Nigeria.

Studies have shown that place of residence has a strong influence on other factors which influence decisions around EBF practice in both developed and developing countries. Among Chinese women, agriculture related occupations were positively associated with early initiation of breastfeeding, current breastfeeding, EBF and predominant breastfeeding among both local and migrant populations [10]. In Dhaka Bangladesh, the prevalence of EBF was lower (36\%) than the national prevalence (55\%) among urban slum dwelling mothers. Moreover, child gender, maternal age, education and household income, infant's age were negatively associated with EBF [11]. In India, there were wide variations in regional prevalence and determinants of EBF, where Southern India had the highest EBF prevalence $(79.2 \%)$ and the North-East reported the lowest (68.0\%), which decreased with infant age, dropping faster in the South compared to the North-East region at 5 months. Higher birth order was a common factor associated with non-EBF across all regions of India, while maternal education is a key modifiable determinant of non-EBF [12]. Moreover, being employed, mother's poor knowledge on what she meant by EBF, mother's poor attitudes towards EBF, unsupported environment in public places, cultural practices discouraged EBF and were independently associated with early cessation of exclusive breastfeeding in Sri Lanka [13]. In Taiwan, education level, primiparity, perceived low milk quantity, and return to work are associated with premature cessation of EBF in Taiwan [14].

In Ethiopia, informally employed mothers and those with six or more family size were more likely to exclusively breastfeed their babies [15]. While attending formal education, low birth order and lack of knowledge about EBF were found to be negatively associated with EBF practice in rural communities of Hula District, Southern Ethiopia [16]. Among rural mothers in Southern Ghana, maternal age, type of occupation, household size and district of residence are determinants of 6 months EBF [17]. In Malawi, age of children was associated with increased odds of EBF, with children aged 3-5 months being less likely to be exclusively breastfed [18]. In Somaliland, EBF practice was associated with having female 
child, lack of formal education, household monthly income 100\$-200\$, lack of husband's support and mothers who were not counseled on breastfeeding during antenatal care [19].

Furthermore, variations existed between ethnic groups globally and in Nigeria on the practice of EBF. For instance, study in China revealed that differences were found in the rates of exclusive breastfeeding among the ethnic groups for children in the first 1, 2, 3, 4, 5 and 6 months of life [20]. In addition, traditional beliefs, myths and misconceptions about EBF and lack of support from husband and family were found to be barriers for proper EBF practice in Aysaita woreda, Afar, Ethiopia [21]. Another study showed that after delivery, the mother has to rest and clean up and some rituals and prayers have to be performed before breast feeding commences in among different ethnic groups in Sub-Sahara Africa [22]. In Nigeria, it has been argued that the reasons adduced for delay initiation of breastfeeding among the Yoruba of South West Nigeria was colostrums, thus supporting the general perception in the study area that in the first three days, the mother's milk is not pure and therefore could harm the infant [23]. In addition, while awaiting the establishment of the clean milk, mothers gave prelacteals in form of boiled water, honey and animal milks. Among the Yoruba in Ibadan, it was reported that mothers believed that feeding infant with water, infant formula/cereal gruels and herbal teas within the first six months of life is necessary stride for child survival [24]. Among the Ibos in South East Nigeria, literature revealed that the reason for low uptake of EBF was because some mothers believed that breast milk is good enough for the baby during the EBF period, while others believe colostrums is harmful to baby, dirty, infected milk and should not be given to the baby [25]. Furthermore, among the Hausa of Adamawa in North East Nigeria, it was shown that the problems that inhibits or reduce the practice of EBF include the assumption that colostrums is stale milk, breast milk lacks sufficient nutrients, expressed breast milk is contaminated milk, thought that food supplements were ideal for infants [26].

In Nigeria, different studies have been carried out on the prevalence and other factors of EBF. For instance, a study revealed that $76.4 \%$ of mothers practiced EBF for a period of $4-6$ months, $38.2 \%$ initiated breastfeeding within 30 minutes and $33.2 \%$ within an hour, while few breastfed on demand [25]. Also, age, educational attainment, EBF knowledge and sources of information about EBF are to be significant predictor of good intention to practice EBF [27]. In addition, rural mothers with low socioeconomic status, early initiation of breastfeeding and delivery assistance have been shown to be more likely to practice EBF [28]. Geopolitical variability in breastfeeding patterns exist also in Nigeria with relatively lower prevalence in the less urbanized areas of Nigeria [29]. Maternal education had also been identified as relevant and related to knowledge of EBF. In this context, mothers with lower education are more likely to breastfeed their infants exclusively than those with higher education [30], while a study revealed no significant relationship between level of education and the practice of EBF [31]. Another study reported that mothers with higher level of education were more likely to breastfeed exclusively for 6 months [25], while [22] reported that mothers with at least primary education engaged in early initiation of breastfeeding compared to mothers with no schooling, while those with no formal education had higher odds of not practicing EBF compared to those with secondary education or higher. Moreover, literature has shown that level of education of mothers had positive associated with the practice of EBF [32]. 
From the foregoing, it is obvious that EBF is very much influenced by ethnic practices and levels of education. However, there is dearth of studies on the combined influences of ethnicity and education on EBF in Nigeria, even as a nationally representative rural-urban comparison of prevalence and factors of EBF have been carried out in the country. Thus, this study examines the association between ethnicity and education with EBF practice in the context of rural-urban residence on a nationally representative population of Nigeria.

\section{Methods}

\section{Data source}

The 2018 Nigeria Demographic and Health Survey (NDHS) is a nationally representative survey, which used a stratified, two-stage cluster design to collect data from a cluster of enumeration areas in the 36 States and the Federal Capital Territory (FCT) of in the country. The sample used for this study consisted of 16,982 urban and 24,834 rural women of childbearing age (15-49 years).

\section{Outcome variable}

The outcome variable indicator used in this study is the practice of exclusive breastfeeding (EBF). Earlier studies have highlighted advantages of EBF to include improved infant nutrition, decreased morbidity and mortality among children under-5 years [33-34]. The composite index of EBF used in this study was derived from the question that asked the proportion of infants $0-5$ months of age who received breast milk as the only source of nourishment (but which allows water and drops of medicines). All responses that used only breast milk and water were coded " 1 " and responses that used breastmilk, water and other forms of food or supplements (mixed feeding pattern, sub-optimal feeding and complimentary feeding) were coded "0"

\section{Independent variables}

The independent variables for this study are divided into the major and minor variables. Thus, the major independent in this study are ethnicity and education. Of the 374 identifiable ethnic groups in Nigeria, the three major ethnic groups are Hausa/Fulani, Igbo and Yoruba. They account for $60 \%$ of population, while the Edo, ljaw, Kanuri, Ibibio, Ebira Nupe, Tiv, and other minority make up the remaining $40 \%$. The middle belt of Nigeria is known for its diversity of ethnic groups, including the Pyem, Goemai and Kofyar [35]. The Hausa/Fulani were categorized as one group in this study because the two tribes share a common language and common set of customs and values [36]. The other minority ethnic groups as one and they were regarded as 'other' in this study. Subsequently, ethnicity was categorized into (i) Igbo (ii) Yoruba Hausa/Fulani and (iv) others. On the other hand, education was categorized into (i) no formal education (ii) primary education (iii) secondary education and (iv) tertiary education. Based on existing studies, we also identified other minor independent socioeconomic predictors of EBF practice. These minor independent variables include age, region, wealth index, employment status, and number of children a woman has. 


\section{Data analysis}

Prior to data analysis, the dataset was weighted to account for differences due to under sampling and over sampling as per the survey design using the Stata svyset command. The analysis of the data involved descriptive statistics of the characteristics of the study population while the bivariate analyses of socio-economic characteristics and exclusive breast-feeding were carried out using Pearson chi-square test. Finally, binary logistic regressions models used to estimate the influence of ethnicity and education with socio-economic predictors of exclusive breast-feeding in Nigeria. The regression coefficients of the independent variables are expressed as Odds Ratio (OR). A variable with Odds Ratio greater than 1.00 implied that the variable increases the likelihood of the outcome (exclusive breastfeeding) while it is the opposite when the OR is less than 1.00. All analyses were the basis of rural/urban places of residence. Consequently, two regression models are generated for this study namely models 1 and 2 . Model 1 is the unadjusted model of exclusive breast-feeding and the major independent variables of ethnicity and education. On the other hand, model 2 is the adjusted model of exclusive breast-feeding and all the independent variables. Each of models 1 and 2 are subdivided in $A$ and $B$ where $A$ refers to the urban population and $B$ represent the rural population.

\section{Results}

\section{Characteristics of the study population}

The results of the study showed that they were more women in the rural areas than in the urban areas. Concerning the three major ethnic groups, the Hausa/Fulani ethnic group constituted more of the respondents in the rural (38.44\%) while the Igbo ethnic group made up $26.06 \%$ of the women in urban areas. More of the urban women $(52.27 \%)$ had secondary while more of the rural women $(47.10 \%)$ had no formal education (Table 1)

\section{TABLE ONE ABOUT HERE}

The South West (23.93\%) and South East (21.29\%) had more of the respondents in the urban areas compared to rural women in the North West (28.65\%) and North East (23.25\%). Also, more of women in urban (35.30\%) and rural (37.34\%) were within the age bracket of 15-24years respectively. Based on wealth status, respondents in the rich category $(68.37 \%)$ and in the poor category $(56.57 \%)$ constituted the majority in the urban and the rural areas respectively. About half of the women in urban areas $(56.24 \%)$ and those in rural areas $(47.05 \%)$ had between $0-2$ children in the study area.

\section{Bivariate analyses of the practice of exclusive breast-feeding}

The results of the analyses showed significant differences in the practice of EBF in all the categories of population characteristics in the rural areas with the exception of their employment status while in the urban areas, the population characteristics with significant differences in the practice of EBF were 
education $(\chi 2=11.53 ; p=.001)$, age $(\chi 2=206.7 ; p=.000)$, wealth index $(\chi 2=9.589 ; p=.001)$ region $(\chi 2$ $=14.69 ; p=.05)$, and the number of children each woman has $(\chi 2=69.36 ; p=.000)$.

\section{TABLE TWO ABOUT HERE}

For instance, in the rural areas, while $4.29 \%$ of the women who practiced EBF had tertiary education, $3.07 \%$ of women in the rural areas had primary education. While $4.33 \%$ and $2.86 \%$ of the women who practiced EBF in the urban area had no formal education and had primary education respectively. In addition, $4.86 \%$ of the Yoruba women compared to $2.41 \%$ of the Igbo women practiced EBF in the rural areas. In the urban areas, $3.66 \%$ of the women who practiced EBF were the Yoruba as against $2.92 \%$ of Igbo women.

\section{The predictors of EBF practice in Nigeria}

Generally, the unadjusted models showed that increase in levels of education was significantly associated with decreases in the odds of EBF in both the rural and urban areas (Table 3). However, ethnic differences were significantly associated with practice of EBF in only the rural areas.

\section{TABLE THREE ABOUT HERE}

In the adjusted models which involved the addition of other independent variables, primary education was significantly associated with decreased odds of EBF practice in urban (OR=0.698; $p=.05)$ and rural areas $(\mathrm{OR}=756 ; p=.05)$. On the other hand, respondents from the Hausa/Fulani ethnic group were significantly associated with increased odds of EBF practice in urban areas.

Other specific variables in the adjusted model that had significant association with the likelihood of respondents practicing EBF in urban areas included being aged 25-34 years $(\mathrm{OR}=2.316 ; p=.000)$, and 35 years and above $(\mathrm{OR}=0.536 ; p=.000)$; being residents of North West $(\mathrm{OR}=0.507 ; p=.000)$, having $3-5$ children (OR=2.220; $p=.000)$, and having 6 and above children $(\mathrm{OR}=0.2 .846 ; p=.000)$. For the adjusted model of EBF in rural areas, the variables which had significant association with EBF practice were being a resident of South West $(\mathrm{OR}=1.999 ; p=.000)$, being aged 35 years and above $(\mathrm{OR}=0.377 ; p=.000)$, having $3-5$ children $(\mathrm{OR}=2.494 ; p=.000)$, and having 6 and above children $(\mathrm{OR}=2.654 ; p=.000)$.

\section{Discussion}

Generally, the likelihood of EBF practice varied significantly between respondents from rural and urban areas based on ethnicity and education with the rural respondents showing more like hood of using EBF. The higher rate of EBF practice in the rural area, which also agreed with earlier studies [11]. This higher rate of EBF practice in rural areas may also be due the fact that most of the rural women are housewives who go to farm, market and other places along side with their children. In addition, these rural women have more access to local nutritious foods associated with weaning of children, which energize and enable them mothers to adopt EBF practice more than their urban counterparts. In addition, the ethnicity of the respondents was significantly associated with the practice of EBF in both rural and urban areas. 
However, the rural women of Yoruba ethic group were more significantly associated with higher levels of EBF practice compared to other ethnic groups. The reason for this may be because mothers in the rural area do not have fear for breasts sagging, body fatness and body changes in the whole process of lactation unlike mothers in urban areas who may believe that adopting EBF affects their body physique, thereby making them look unattractive to men. In addition, rural women believe that EBF makes a child to be healthy and build their immune against illnesses and diseases as emphasized by rural healthcare providers who are professionals in child health. The perception justifies the increased EBF in rural areas, especially in the major ethnic groups as noted in earlier studies [11]. In addition, the influence of cultural beliefs and practices of the different ethnic groups in Nigeria on breastfeeding practices may serve as an explanation. In this context, Yoruba women were more involved in EBF in both rural and urban areas. This finding agree with earlier study as the Yorubas are known for strict adherence to cultural values towards herbal medication and believe that feeding infant with water, infant formula/cereal gruels and herbal teas within the first six months of life is necessary stride for child survival [24]. This finding was in disagreement with the another earlier findings [23] which argued that the reasons adduced for delay initiation of breastfeeding among the Yoruba of South West Nigeria was colostrums being the first mother's milk is not pure and therefore could harm the infant. As a result, mothers gave prelacteals in form of boiled water, honey and animal milks to new born baby while awaiting the establishment of the clean milk.

Furthermore, this study revealed that mothers with higher levels of education were significantly associated reduced levels of EBF practice in both urban and rural areas. This agrees with earlier literature, as mothers with lower levels of education are more likely to breastfeed their infants exclusively than those with higher levels of education [22-30]. This may be attributed to the fact that mothers with higher levels of education are likely to be engaged in the formal employment sector, which does not avail them with ample time and strength to adopt EBF practice. In addition, with formal workplace policies usually restrict these mothers with higher levels of education from taking their children to work in order to breastfeed them as when and due in accordance with WHO recommendation on EBF practice. Finally, geographical location and some socioeconomic characteristics were significantly associated with EBF practice in both urban area and rural areas in the study area. The results agree with various earlier studies which showed geographical location had significant association with EBF practice [12-13], while maternal age, household income, infants age were significantly associated with decreased levels of EBF as a study has shown in Bangladesh [11].

\section{Conclusion}

This study has provided empirical evidence on the association between ethnicity, levels of education and exclusive breastfeeding in Nigeria. The results of this study revealed that majority of mothers in the rural areas adopted exclusive breastfeeding practices. In addition, the study revealed variations in predictors of EBF across the ethnic groups between rural-urban areas in Nigeria. The fear of breasts sagging and body fatness was common among the urban mothers due to their level of education and trending issues on body trimming in order to be attractive to men. Conversely, the rural respondents engaged more in EBF 
practice as they were less likely to be concerned with their body changes in the whole process of lactation or the issue of becoming unattractive to men. To eradicate these perceptions especially among mothers with higher levels of education in the urban areas, more sensitization campaigns by healthcare personnel and social workers on the need to incorporate EBF practice into formal employment workplaces work ethics should be carried out with employers of labor in urban areas. In addition, campaigns to encourage ethnic practices to promote the tremendous benefits of EBF should be mounted at antenatal and postnatal clinics in both rural and urban areas. This will help in improving EBF practice across the ethnic groups, and translate to reduction of infection and diseases associated with complementary and suboptimal feeding. It will also erase fears of mothers concerning their body physique because of adopting EBF for their infants.

\section{Abbreviations}

CAPI : Computer-assisted Personal Interviewing

EBF: Exclusive Breastfeeding

NDHS: Nigeria Demographic Health Survey

FCT: Federal Capital Territory

NHREC: National Health Research Ethics Committee of Nigeria

NEC: Necrotizing Enterocolitis

OR: Odds Ratio

\section{Declarations}

\section{Ethics approval and consent to participate}

The survey protocol was reviewed and approved by the National Health Research Ethics Committee of Nigeria (NHREC) and the ICF Institutional Review Board. After all questionnaires were finalized in English, they were translated into Hausa, Yoruba, and Igbo. The 2018 NDHS used computer-assisted personal interviewing (CAPI) for data collection.

\section{Consent for publication}

Not applicable

\section{Availability of data and materials}

The dataset is publicly available on the (Demographic and Health Survey (DHS) website 
(https://dhsprogram.com/data/availabledatasets.cfm)

\section{Competing interests}

The authors declare that they have no competing interest

\section{Funding}

None

\section{Authors' contributions}

POM and NPA conceptualized the study and helped to drafted the introduction. NPA contributed in drafting the introduction and discussed the findings. CKA was responsible for data analysis and interpretation. All the authors reviewed the final draft of the manuscript.

\section{Acknowledgements}

Not applicable

\section{References}

1. Vaucher J. Breastfeeding in Developing Countries: The Myths, the Problems and the Progress. 2018. Available from: https://www.breastfeeding.org/breastfeeding-in-developing-countries-the-myths-theproblems-and-the-progress.

2. Wana AD. Assessment of knowledge, attitudes and practice on exclusive breastfeeding of child bearing mothers in Boditi town, Southern Ethiopia: A cross-sectional study. J Bio, Agric Healthcare. 2017;7:31-42.

3. Ike MN. Utilization of exclusive breastfeeding methods among nursing mothers in Nigeria. Chen, J., Xin, T., Gaoshan, J., Li, Q., Zou, K., Tan, SMed J Soc Sci. 2013;4:69-76.

4. Oddy W, Jianghong LI, Monique R, Andrew, JO. The long-term effects of breastfeeding on development. 2011. Available from:

http://www.cdn.intechogen.com/pdfs/31651/InTech_The_long_effects_of_breast feeding_on_development.pdf.

5. World Health Organization (WHO). Breastfeeding. 2020. Available from: https://www.who.int/healthtopics/breastfeeding\#tab=tab_1.

6. Adebowale N. World Breastfeeding Week: D8 countries, UNICEF want breastfeeding promoted. 2019. Available from: https://www.premiumtimesng.com/news/more-news/344930-world- breastfeedingweek-d8-countries-unicef-want-breastfeeding-promoted.html.

7. World Health Organization (WHO). Infant and young child feeding. 2020. Available from: https://www.who.int/news-room/fact-sheets/detail/infant-and-young-child-feeding. 
8. World Breastfeeding Week Report. Sustaining breastfeeding together. 2017. Available from: www.ilca.org/main/global-health/world-breastfeeding-week.

9. Atoyebi 0. 73\% Nigerian children denied exclusive breastfeeding -FG. Punch Newspapers, $7^{\text {th }}$ August. 2019. Available from: https://punchng.com/73-nigerian-children-denied-exclusivebreastfeeding-fg/.

10. Chen J, Xin T, Gaoshan J, Li Q, Zou K, Tan S, et al. The association between work related factors and breastfeeding practices among Chinese working mothers: a mixed-method approach. Int. breastfeed J. 2019;14:1-13.

11. Khatun H, Comins CA, Shah R, Islam MM, Choudhury N, Ahmed T. Uncovering the barriers to exclusive breastfeeding for mothers living in Dhaka's slums: a mixed method study. Int. Breastfeed J. 2018;13:1-11.

12. Ogbo FA, Dhami MV, Awosemo AO, Olusanya BO, Olusanya J, Osuagwu UL, et al. Regional prevalence and determinants of exclusive breastfeeding in India. Int. Breastfeed J. 2019;14:1-12.

13. Ratnayake HE, Rowe D. Prevalence of exclusive breastfeeding and barriers for its continuation up to six months in Kandy district, Sri Lanka. Int. Breastfeed J. 2018;13:1-8.

14. Chang P, Li S, Yang H, Wang L, Weng C, Chen K, et al. Factors associated with cessation of exclusive breastfeeding at 1 and 2 months postpartum in Taiwan. Int. Breastfeed J . 2019;14:1-7.

15. Ahmed AE, Salih OA. Determinants of the early initiation of breastfeeding in the Kingdom of Saudi Arabia. Int. Breastfeed J. 2019;14:1-13.

16. Shibru H, Berhan M, Negash W. Sub-optimal breast feeding and its associated factors in rural communities of Hula District, Southern Ethiopia: A cross-sectional study. Ethiop J Health Sci. 2018;28:49-62.

17. Manyeh AK, Amu A, Akpakli DE, Williams JE, Gyapong M. Estimating the rate and determinants of exclusive breastfeeding practices among rural mothers in Southern Ghana. Int Breastfeed J. 2020;15:1-9

18. Nkoka O, Ntenda PAM, Kanje V, Milanzi EB, Arora A. Determinants of timely initiation of breastmilk and exclusive breastfeeding in Malawi: a population-based cross-sectional study. Int. Breastfeed J. 2019;14:1-9.

19. Jama A, Gebreyesus H, Wubayehu T, Gebregyorgis T, Teweldemedhin M, Berhe, T, et al. Exclusive breastfeeding for the first six months of life and its associated factors among children age 6-24 months in Burao district, Somaliland. Int. Breastfeed J. 2020;15:1-8.

20. Qu P, Wang T, Liu F, Dang, S, Zeng, L, Yan H. Breast-feeding patterns of ethnic groups in rural western China. Public Health Nutri. 2015;18:3386-3393.

21. Tsegaye M, Ajema D, Shiferaw S, Yirgu R. Level of exclusive breastfeeding practice in remote and pastoralist community, Aysaita woreda, Afar, Ethiopia. Int. Breastfeed J. 2019;14:1-15.

22. 22. Issaka Al, Agho KE, Renzaho Prevalence of key breastfeeding indicators in 29 sub-Saharan African countries: a meta-analysis of demographic and health surveys (2010-2015). BMJ Open. 
2017;e014145.

23. Oche MO, Umar AS, Ahmed H. Knowledge and practice of exclusive breastfeeding in Kwara, Nigeria. Afri Health Sci J. 2011;11:518-523

24. Akinremi Z, Folaka OS. Knowledge and attitude of exclusive breastfeeding among hair dresser apprentices in Ibadan, Nigeria. British J Med Medical Res. 2015;5:376-385.

25. Nwali IN, Agboeze J, Ejikeme BN, Anozie OB, Onwe B. Breastfeeding awareness and practices in Abakaliki, Southeast Nigeria. Scientific Research. 2016;6:861-873.

26. Tyndall A, Kamai R, Chanchangi D. Knowledge, attitudes and practice on EBF on Adamawa, Nigeria. Amer J Pub Res. 2016;4:112-119.

27. Ihudiebube-Splendor C H., Okafor CB, Anarado AN, Jisieike-Onuigbo NN, Chinweuba AU, Nwaneri AC, et al. Exclusive breastfeeding knowledge, intention to practice and predictors among primiparous women in Enugu South-East, Nigeria. J Pregnancy 2019;1-8.

28. Hitachi M, Honda S, Kaneko S, Kamiya Y. Correlates of exclusive breastfeeding practices in rural and urban Niger: a community-based cross-sectional study. Int. Breastfeed J. 2019;14:1-9

29. Ogbo FA, Agho KE, Page A. Determinants of suboptimal breastfeeding practices in Nigeria: evidence from the 2008 demographic and health survey. BMC Public Health. 2015;15:259.

30. Hossain M, Islam A, Kamarul T, Hossain G. Exclusive breastfeeding practice during first six months of an infant's life in Bangladesh: a country based cross-sectional study. BMC Pediatr. 2018;18:2-9.

31. Ojong ID, Chiotu CN, Nlumanze FF. Factors influencing the practice of exclusive breastfeeding among mothers in tertiary health facility in Calabar, Cross River State, Nigeria. Amer J Nur Sci. 2015;4:16-21.

32. Anazonwu NP, Ngwu CN, Obasi-Igwe I. Socio-demographic predictors of exclusive breastfeeding practices in Nsukka urban area of Enugu State. Int. J Kinetics Health Edu (IJoHKHE). 2017;3:9-17

33. Ladomenou F, Moschandreas J, Kafatos A, et al. Protective effect of exclusive breastfeeding against infections during infancy: a prospective study. Arch Dis Child. 2010;95:1004-8.

34. Black RE, Victora CG, Walker SP. Maternal and child under nutrition and overweight in low-income and middle-income countries. Lancet. 2013;382:427-451.

35. Uthman OA. Geographical variations and contextual effects on age of initiation of sexual intercourse among women in Nigeria: a multilevel and spatial analysis. Int. J Health Geo. 2008;7:27

36. Adedini SA, Odimegwu, C, Imasiku ENS, Ononokpono DN. Ethnic differentials in under-five mortality in Nigeria. Ethnic Health. 2015;20:145-162.

\section{Tables}

Table 1: Characteristics of the study population 


\begin{tabular}{|c|c|c|}
\hline & Urban Population & Rural Population \\
\hline Variables & $n(\%)$ & $n(\%)$ \\
\hline \multicolumn{3}{|l|}{ Ethnicity } \\
\hline Igbo & $4,425(26.06)$ & $2,286(9.21)$ \\
\hline Yoruba & $3,911(23.03)$ & $1,460(5.88)$ \\
\hline Hausa/Fulani & $4,173(24.57)$ & $9,545(38.44)$ \\
\hline Others & $4,473(26.34)$ & $11,543(46.48)$ \\
\hline \multicolumn{3}{|l|}{ Education } \\
\hline None & $2,702(15.91)$ & $11,696(47.10)$ \\
\hline Primary & $2,346(13.81)$ & $4,037(16.26)$ \\
\hline Secondary & $8,876(52.27)$ & 7,818(31.48) \\
\hline Tertiary & $3,058(18.01)$ & $1,283(5.17)$ \\
\hline \multicolumn{3}{|l|}{ Age } \\
\hline $15-24$ years & $5,994(35.30)$ & $9,272(37.34)$ \\
\hline $25-34$ years & $5,454(32.12)$ & 7,742(31.18) \\
\hline $35+$ years & $5,534(32.59)$ & $7,820(31.49)$ \\
\hline \multicolumn{3}{|l|}{ Wealth Index } \\
\hline Poor & $2,043(12.03)$ & $14,049(56.57)$ \\
\hline Middle & $3,328(19.60)$ & $5,531(22.27)$ \\
\hline Rich & $11,611(68.37)$ & $5,254(21.16)$ \\
\hline \multicolumn{3}{|l|}{ Employed } \\
\hline No & 5,736(33.78) & $9,029(36.36)$ \\
\hline Yes & $11,246(66.22)$ & $15,805(63.64)$ \\
\hline \multicolumn{3}{|l|}{ Region } \\
\hline North Cent & $2,627(15.47)$ & $5,145(20.72)$ \\
\hline North East & 1,864(10.98) & $5,775(23.25)$ \\
\hline North West & $3,014(17.75)$ & $7,115(28.65)$ \\
\hline South East & $3,615(21.29)$ & $1,955(7.87)$ \\
\hline South South & 1,799(10.59) & $3,279(13.20)$ \\
\hline
\end{tabular}




\begin{tabular}{|lll|}
\hline South West & $4,063(23.93)$ & $1,565(6.30)$ \\
\hline Number of Children & & \\
\hline 0-2 children & $9,551(56.24)$ & $11,685(47.05)$ \\
\hline 3-5 children & $4,831(18.45)$ & $7,090(28.55)$ \\
\hline 6+ children & $2,600(15.31)$ & $6,059(24.40)$ \\
\hline TOTAL & $\mathbf{1 6 , 9 8 2 ( 1 0 0 . 0 0 )}$ & $\mathbf{2 4 , 8 3 4 ( 1 0 0 . 0 0 )}$ \\
\hline
\end{tabular}

Table 2: Bivariate analyses of the practice of exclusive breastfeeding 


\begin{tabular}{|c|c|c|c|c|}
\hline & Urban & & Rural & \\
\hline & No (\%) & Chi-square & No $(\%)$ & Chi-square \\
\hline Ethnicity & & 4.607 & & $16.95^{* *}$ \\
\hline Igbo & $129(2.92)$ & & $55(2.41)$ & \\
\hline Yoruba & $143(3.66)$ & & $71(4.86)$ & \\
\hline Hausa/Fulani & 148(3.55) & & $338(3.54)$ & \\
\hline Others & $142(3.17)$ & & $434(3.76)$ & \\
\hline Education & & $11.53^{* *}$ & & $19.49 * * *$ \\
\hline None & $117(4.33)$ & & $479(4.10)$ & \\
\hline Primary & $67(2.86)$ & & 124(3.07) & \\
\hline Secondary & $287(3.23)$ & & $240(3.07)$ & \\
\hline Tertiary & $91(2.98)$ & & $55(4.29)$ & \\
\hline Age & & $206.7 * * *$ & & $88.86 * * *$ \\
\hline $15-24$ years & $116(1.94)$ & & $289(3.12)$ & \\
\hline $25-34$ years & $337(6.18)$ & & $406(5,24)$ & \\
\hline $35+$ years & $109(1.97)$ & & $203(2.60)$ & \\
\hline Wealth Index & & $9.589 * *$ & & $8.343^{*}$ \\
\hline Poor & $89(4.36)$ & & $544(3.87)$ & \\
\hline Middle & 117(3.52) & & $167(3.02)$ & \\
\hline Rich & $356(3.07)$ & & $187(3.56)$ & \\
\hline Employed & & 0.066 & & 0.280 \\
\hline No & 187(3.26) & & $319(3.53)$ & \\
\hline Yes & $375(3.33)$ & & $579(3.66)$ & \\
\hline Region & & $14.69 *$ & & $60.38 * * *$ \\
\hline North Cent & $99(3.77)$ & & 195(3.79) & \\
\hline North East & $67(3.59)$ & & $251(4.35)$ & \\
\hline North West & $83(2.75)$ & & $239(3.36)$ & \\
\hline South East & $107(2.96)$ & & $38(1.94)$ & \\
\hline South South & $46(2.56)$ & & $83(2.53)$ & \\
\hline
\end{tabular}




\begin{tabular}{|llll|}
\hline South West & 160(3.94) & 92(5.88) \\
\hline No. of Children & & 69.36*** & 78.92*** \\
\hline$<2$ children & $225(2.36)$ & $310(2.65)$ \\
\hline $3-5$ children & $239(4.95)$ & $365(5.15)$ \\
\hline 6+ children & $98(3.77)$ & $223(3.68)$ \\
\hline
\end{tabular}

Table 3: Logistic regression of predictors of exclusive breastfeeding 


\begin{tabular}{|c|c|c|c|c|}
\hline Variables & Urban & Urban & Rural & Rural \\
\hline \multicolumn{5}{|l|}{ Ethnicity } \\
\hline Igbo & 1.000 & 1.000 & 1.000 & 1.000 \\
\hline Yoruba & 1.261 & 1.087 & $2.005^{\star \star \star}$ & 0.583 \\
\hline Hausa/Fulani & 1.057 & 1.483 & 1.150 & $0.577^{*}$ \\
\hline Others & 1.050 & 1.215 & $1.438^{\star}$ & 0.757 \\
\hline \multicolumn{5}{|l|}{ Education } \\
\hline None & 1.000 & 1.000 & 1.000 & 1.000 \\
\hline Primary & $0.640 * *$ & $0.698^{\star}$ & $0.683^{\star \star \star}$ & $0.756^{*}$ \\
\hline Secondary & $0.722^{\star \star}$ & 0.973 & $0.673^{\star \star \star}$ & 0.829 \\
\hline Tertiary & $0.656^{\star *}$ & 0.932 & 0.923 & 1.217 \\
\hline \multicolumn{5}{|l|}{ Age } \\
\hline $15-24$ years & & 1.000 & & 1.000 \\
\hline $25-34$ years & & $2.316^{\star \star \star}$ & & 0.936 \\
\hline $35+$ years & & $0.536 * \star \star$ & & $0.377^{\star \star *}$ \\
\hline \multicolumn{5}{|l|}{ Wealth Index } \\
\hline Poor & & 1.000 & & 1.000 \\
\hline Middle & & 0.774 & & 0.880 \\
\hline Rich & & $0.663^{\star *}$ & & 1.160 \\
\hline \multicolumn{5}{|l|}{ Employed } \\
\hline No & & 1.000 & & 1.000 \\
\hline Yes & & $0.816^{\star}$ & & 0.993 \\
\hline \multicolumn{5}{|l|}{ Region } \\
\hline North Cent & & 1.000 & & 1.000 \\
\hline North East & & 0.780 & & 1.110 \\
\hline North West & & $0.507 * \star \star$ & & 0.902 \\
\hline South East & & 1.026 & & $0.407^{\star *}$ \\
\hline South South & & 0.815 & & $0.694^{\star *}$ \\
\hline South West & & 1.393 & & $1.999 * \star \star$ \\
\hline
\end{tabular}




\begin{tabular}{|lll|}
\hline No. of Children & & \\
\hline$<2$ children & 1.000 & 1.000 \\
\hline $3-5$ children & $2.220^{\star * *}$ & $2.494^{\star * *}$ \\
\hline $6+$ children & $2.846^{\star * *}$ & $2.654^{\star * *}$ \\
\hline
\end{tabular}

